\title{
False arteriovenous shunts of the spine
}

\section{Ian C Duncan \\ FFRad(D)SA}

Unitas Interventional Unit PO Box 14031 Lyttelton 0140

\section{Introduction}

Arteriovenous shunts of the spine generally fall into one of four main categories, namely the dural shunt, the intramedullary and perimedullary shunts and the rare shunts associated with the metameric arteriovenous spinal syndromes (Cobb syndrome).

Features common to these shunts at myelography, CT and MRI include dilated serpiginous vascular structures within the subarachnoid space, the presence of a nidus in intramedullary nidal-type arteriovenous malformations, and the presence of cord oedema. Although these features are indicative of the presence of a spinal arteriovenous shunt, many are nonspecific and often angiography is required to properly categorise the type and location of shunt present.

We describe five cases in this pictorial essay, four of whom were referred as possible 'arteriovenous malformations' on the basis of myelography or sectional imaging and who were all subjected to spinal angiography, which proved normal in each case. The case of venous congestion secondary to lumbar spinal stenosis was confirmed as such at surgery and did not undergo angiography. Many radiologists and clinicians involved with spinal imaging and management are undoubtedly aware of these arteriovenous shunt mimics, but as shown in the investigation of these cases there are still those who are not. This pictorial essay has been presented to assist in the recognition of these variants.

\section{Normal spinal vascular anatomy}

With the vastly improved image quality produced by modern MRI scanners, normal non-dilated vascular structures can be visualised on sectional and MR myelographic images (Figs $1 \mathrm{a}, \mathrm{b}$ ). Similar findings can occasionally be seen with conventional myelography.

Generally the vascular structures identified are those of the larger anterior or ventral spinal axis or the socalled 'anterior spinal artery' (ASA). The ASA has a diameter of up to $0.5 \mathrm{~mm}$ in the cervical region and up to $0.8 \mathrm{~mm}$ in the lumbosacral region. The diameter of supplying radicular arteries may also vary from 0.4 to $0.6 \mathrm{~mm}$ in the cervical region, and from 0.5 to $1.2 \mathrm{~mm}$ in the thoracolumbar region (the artery of the lumbar enlargement or artery of Adamkiewicz). ${ }^{1}$ Similarly, parts of the extrinsic venous system of the cord that consists of the pial venous network, the longitudinal dorsal and ventral sulcal veins and radicular veins can also reach up to and sometimes exceed $1.0 \mathrm{~mm}$ in diameter.

Sub-millimetre resolution is now possible, with modern MRI scanners allowing visualisation of these normal vascular structures. However, great care must be taken to fully exclude a small or early arteriovenous shunt, which may necessitate spinal angiography (Figs 1c-g).

\section{Venous con- gestion in lumbar spinal stenosis}

The phenomenon of intrathecal venous congestion and dilatation secondary to spinal stenosis has been



Fig. 1a. MR myelogram, frontal projection, showing normal vessels on the surface of the cord in the lumbar region 


\section{PICTORIAL ESSAY}

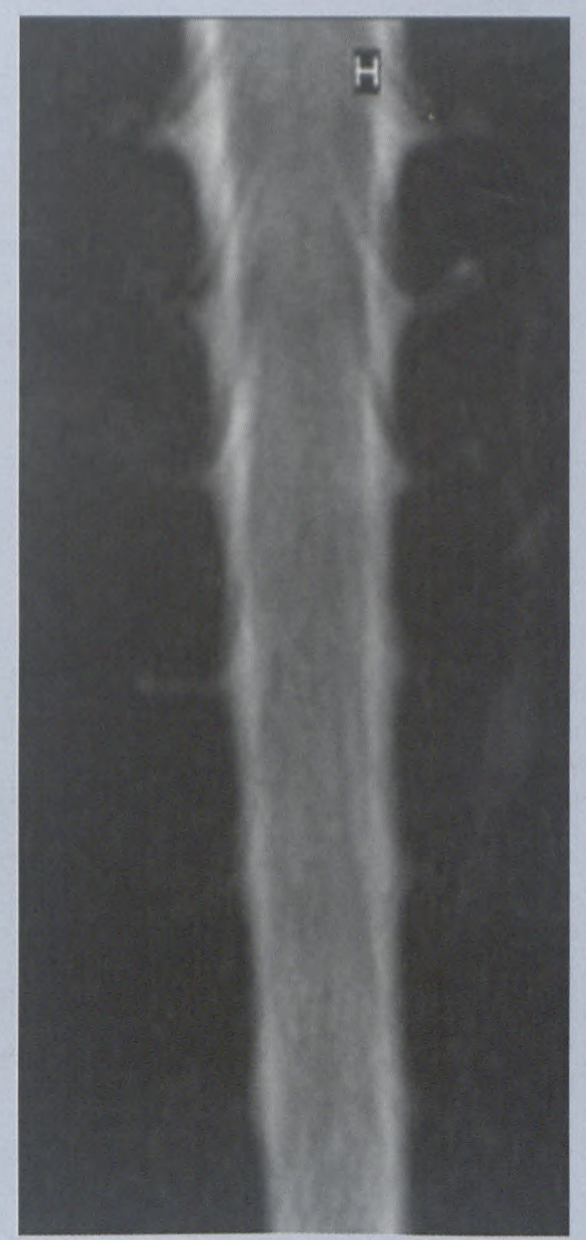

Fig. 1b. Same case showing normal vessels in the cervical region. As this patient had symptoms suggestive of a possible spinal vascular abnormality she underwent a complete spinal angiogram which was normal.

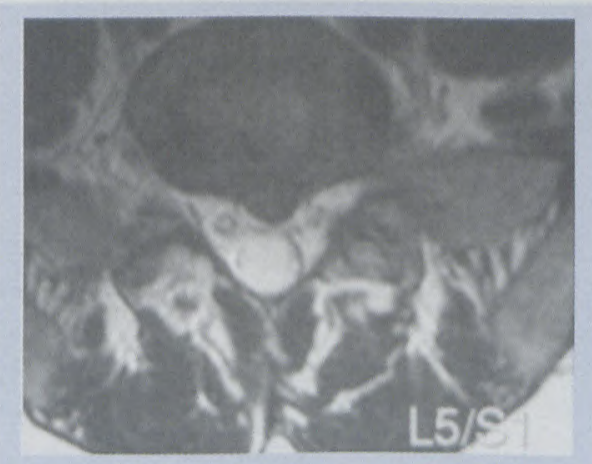

Fig. 1c. A 39-year-old man presents with lower back pain and neurological symptoms related to a focal herniation of the L5/S1 disc.

documented and is a not infrequent finding at surgery for spinal stenosis. ${ }^{2}$ The dilated veins are seen as serpiginous filling defects at myelography

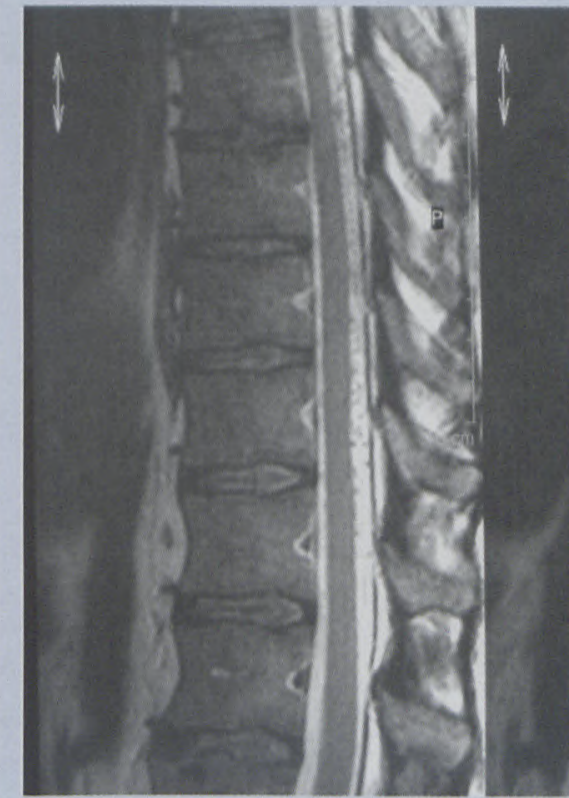

Fig. 1d. As an incidental discovery in the dorsal region a number of serpiginous filling defects are seen in the dorsal subarachnoid space.



Fig. 1e. MR myelogram, upper dorsal level, showing the thin serpiginous filling defects around the cord representing dilated dorsal perimedullary veins.

and enhancing structures on Gadolinium-enhanced MR imaging (Figs $2 \mathrm{a}-\mathrm{c}$ ). Similar serpiginous filling defects at myelography have also previously been ascribed to elongation or 'redundancy' of nerve roots.

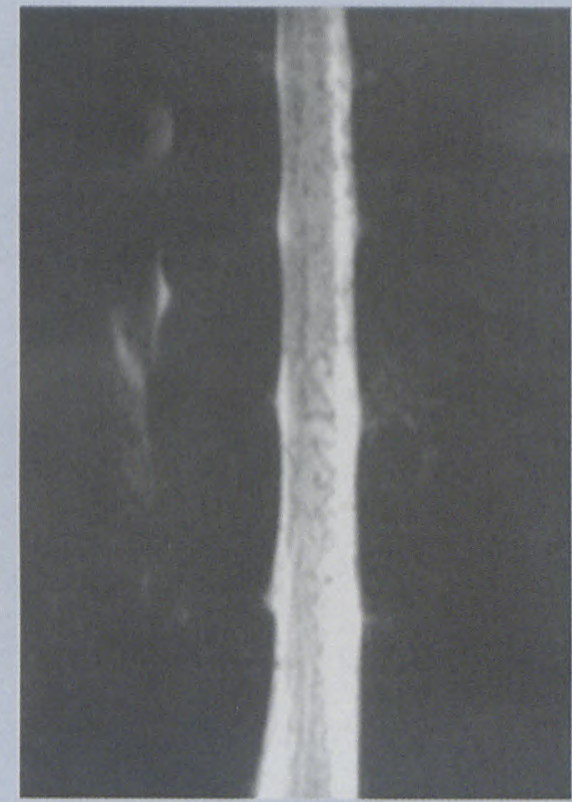

Fig. 1f. MR myelogram, lower dorsal level, showing the lower extent of the distended dorsal perimedullary veins.



Fig. 1g. Digital spinal arteriogram, right 77 intercostal artery, showing the presence of a dural artenovenous fistula. This was clinically occult.

\section{Cord ischaemia/oede- ma in cervical spondylosis}

High signal intensity can occasionally be seen on MR imaging within the cervical cord at and adjacent to the site of cervical canal stenosis (Figs $3 \mathrm{a}-\mathrm{d}){ }^{4.5}$ These changes are thought to represent one or a combination of 




Diagnostics

Gadopentetate dimeglumine
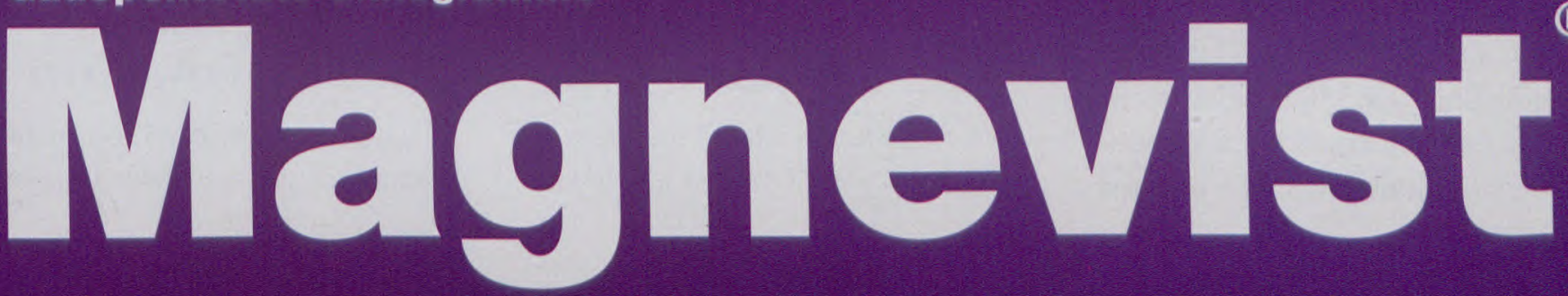

@

Further information available on request from 


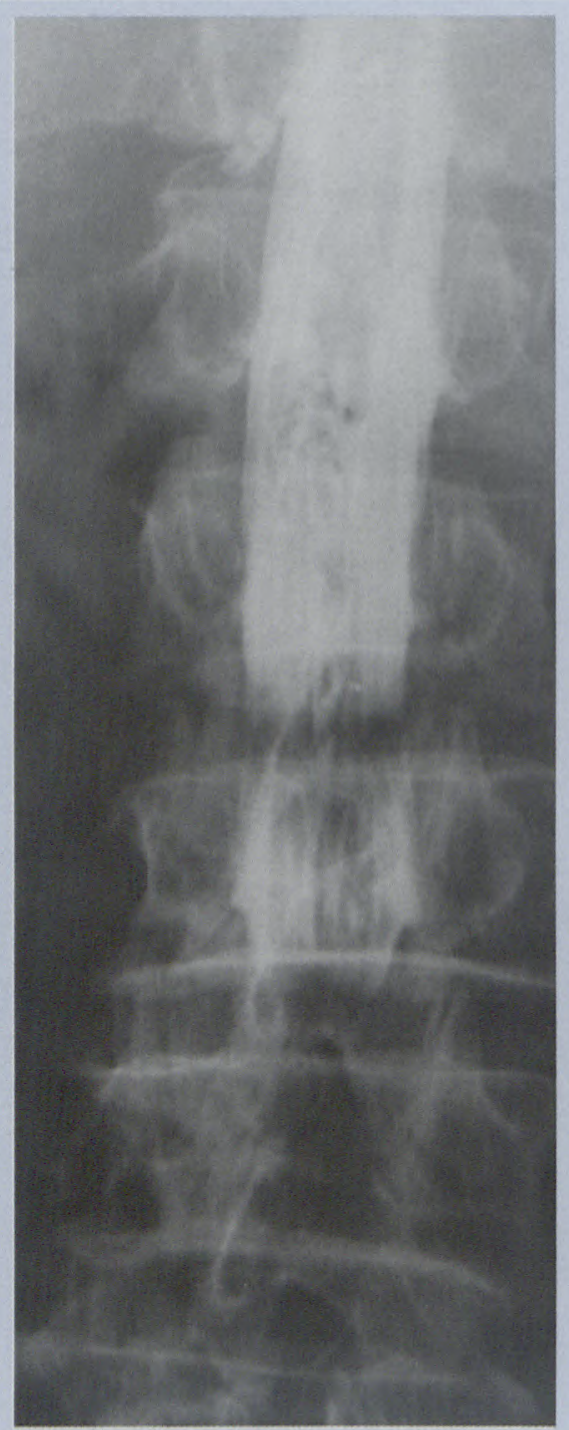

Fig. 2a. Lumbar myelogram, AP projection, showing spinal stenosis at the $L 3 / 4$ level and blockage of the canal at $L 4 / 5$. Numerous serpiginous filling defects are seen in the subarachnoid space.

oedema, gliosis, demyelination, myelomalacia or any combination of these changes. Current theory holds that these changes are due to arterial and/or venous ischaemia. Some of these imaging changes resolve after surgical decompression, more suggestive of venous congestion than irreversible arterial or venous infarction. High signal intensity within the cord is non-specific and may be the only positive finding at $\mathrm{MR}$ imaging in certain cases, with small dural or perimedullary shunts where the involved

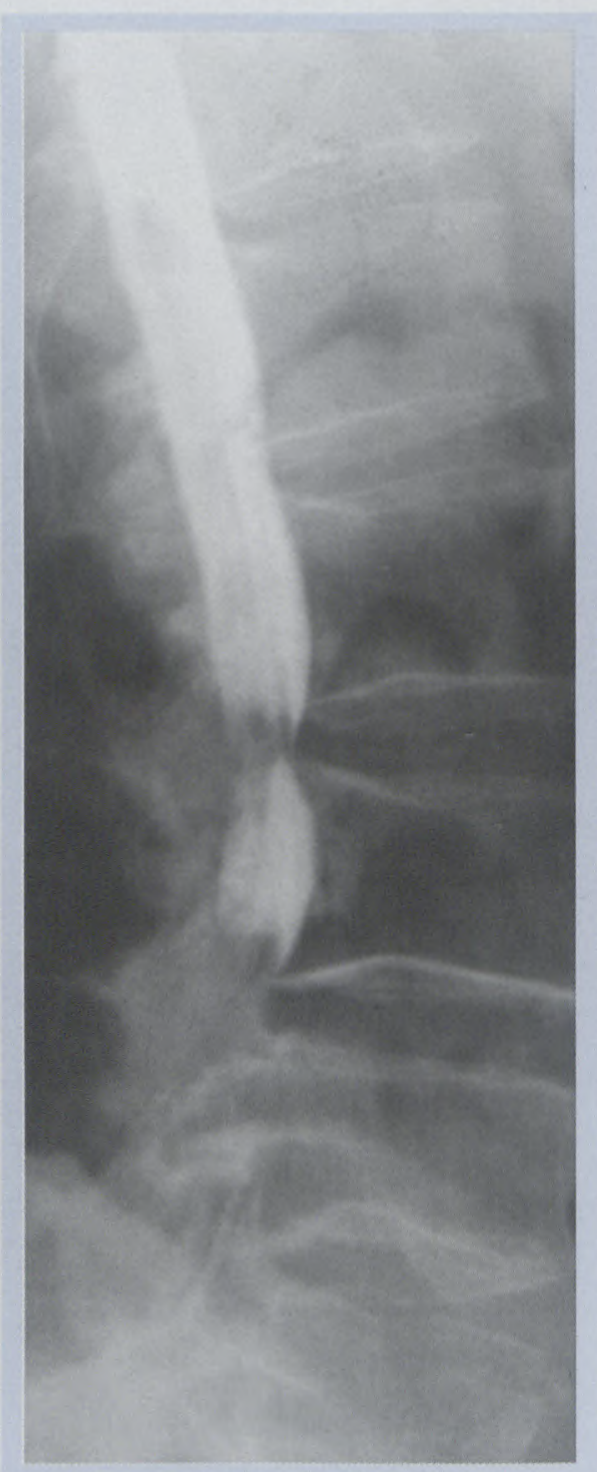

Fig. 2b. Same study, lateral projection.

vessels are too small to be seen by non-invasive means. The cord oedema in such cases is related to combined venous hypertension and congestion. This is often seen in the lower thoracic and lumbar levels rather than in the cervical region due to the effects of gravity and spontaneous thrombotic occlusion of exit radicular veins at these lower levels (Fig 3e).

\section{CSF flow artefact}

CSF pulsation artefact manifests as 'flow voids' within the CSF and is par-



Fig. 2c. Enlarged view showing detail of the serpiginous filling defects shown later at surgery to be dilated, congested intrathecal veins.

ticularly evident on $\mathrm{T} 2$ weighted MRI sequences (Figs $4 \mathrm{a}$-e). The signal loss resulting in these 'voids' is due to phase shifts related to different CSF flow velocities and directions during the cardiac and respiratory cycles. Specialised fast scanning and flow reduction techniques can be utilised to reduce (but usually not completely obliterate) these artefacts (Fig 4f). The artefactual 'voids' are generally larger in diameter than most dilated arteries or veins, even those related to a spinal macrofistula. In addition there is no continuity between the areas of 'void' on sequential images.

\section{Spinal cord cavernous malformation}

Cavernomas or cavernous malformations of the spinal cord are rare, 


\section{PICTORIAL ESSAY}

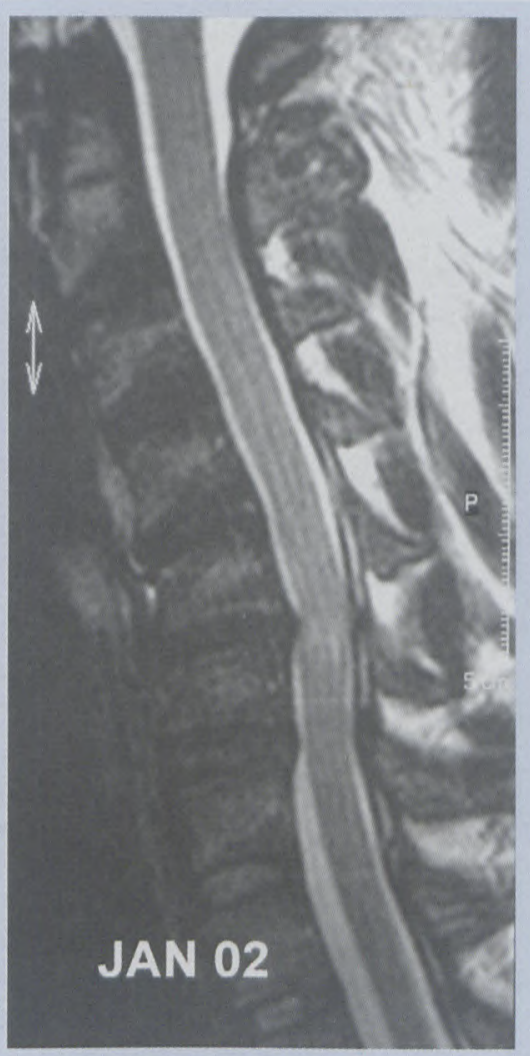

Fig. 3a. Sagittal T2 weighted MR scan of the cervical spine showing early cervical stenosis at C5/6 and early degeneration at C6/7. Mild cord oedema is evident.

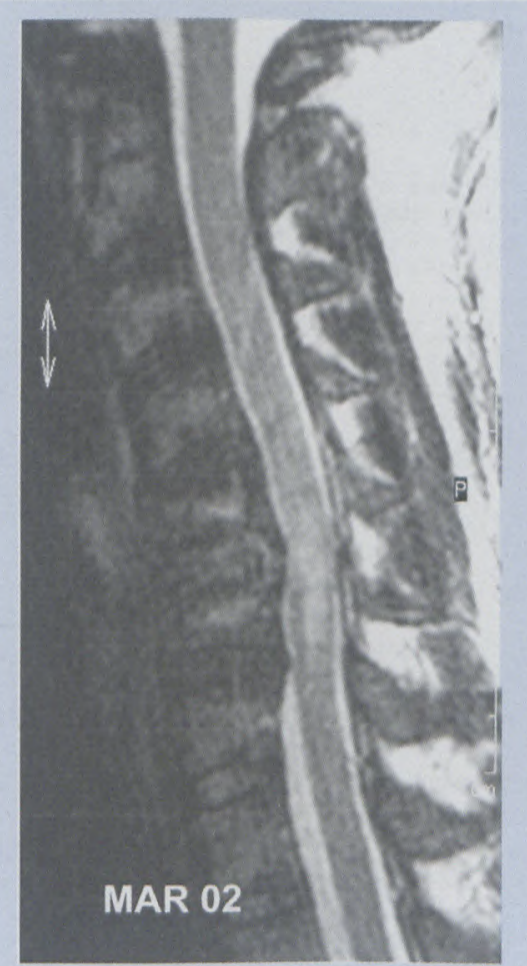

Fig. 3b. Two months later the symptoms have worsened as has the degree of stenosis. The cord oedema is now more extensive.

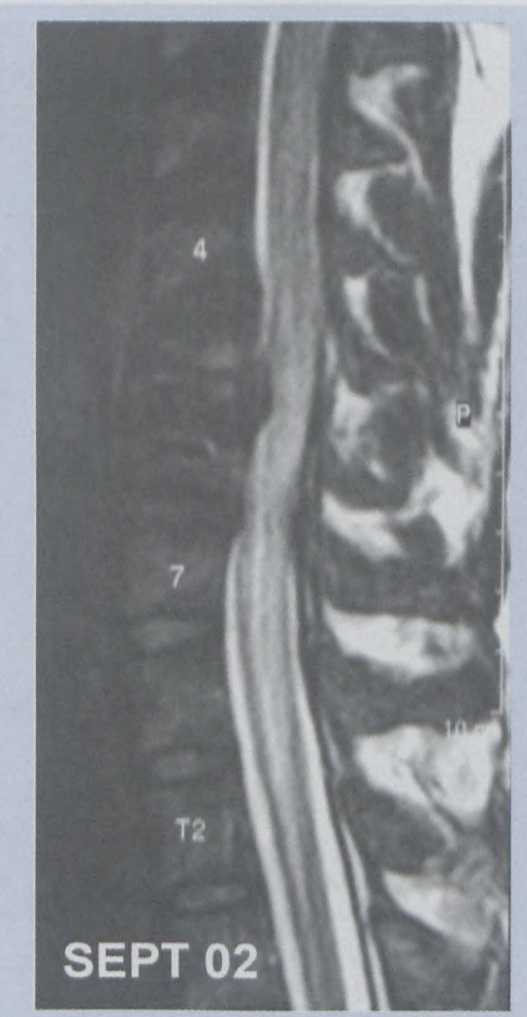

Fig. 3c. Seven months later and the stenosis and cord oedema have progressed further as have the clinical symptoms. Given the amount of oedema present a spinal angiogram was performed to exclude a vascular shunt. The angiogram is normal.

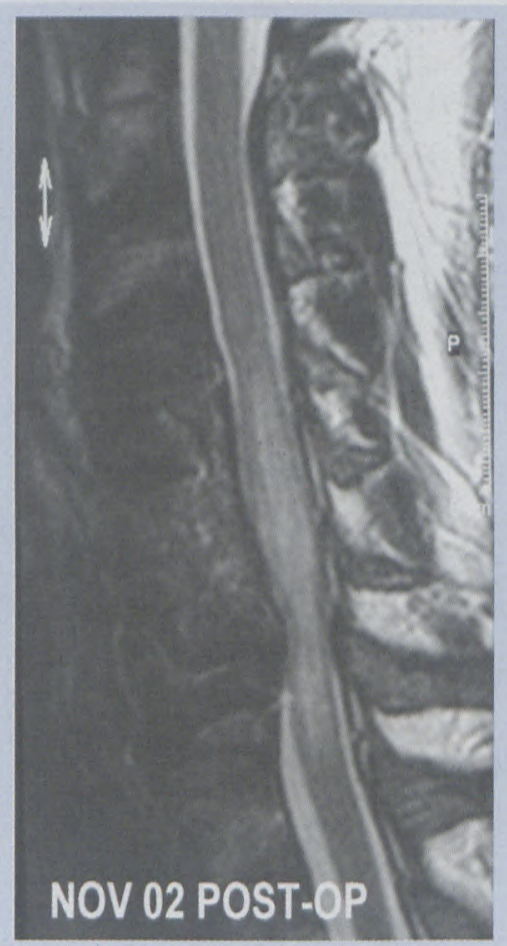

Fig. 3d. Two months post anterior decompression and fusion. The cord oedema is subsiding and there has been excellent clinical improvement as well.

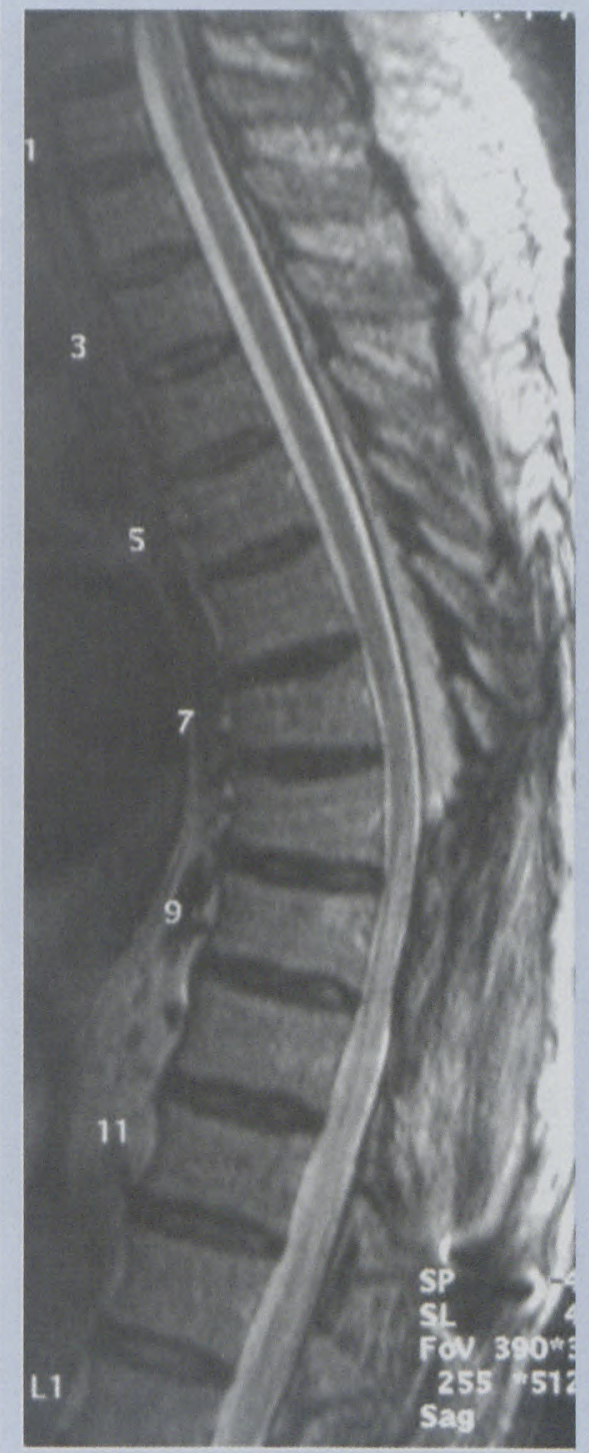

Fig. 3e. Sagittal T2 MR image showing oedema in the lower thoraco-lumbar cord in a patient with a lumbar dural AV fistula.

accounting for less than $5 \%$ of cavernomas of the central nervous system. ${ }^{6}$

Although classified as vascular malformations they are not high-flow lesions. Their radiographic appearance within the cord is similar to that within the brain, i.e. a reticulated central area often described as 'popcorn'like with multiple blood or clot-filled channels which can be dark or brighter on both $\mathrm{T} 1$ and $\mathrm{T} 2$-weighted images depending upon the age and nature of the blood products within the central channels, surrounded by a 


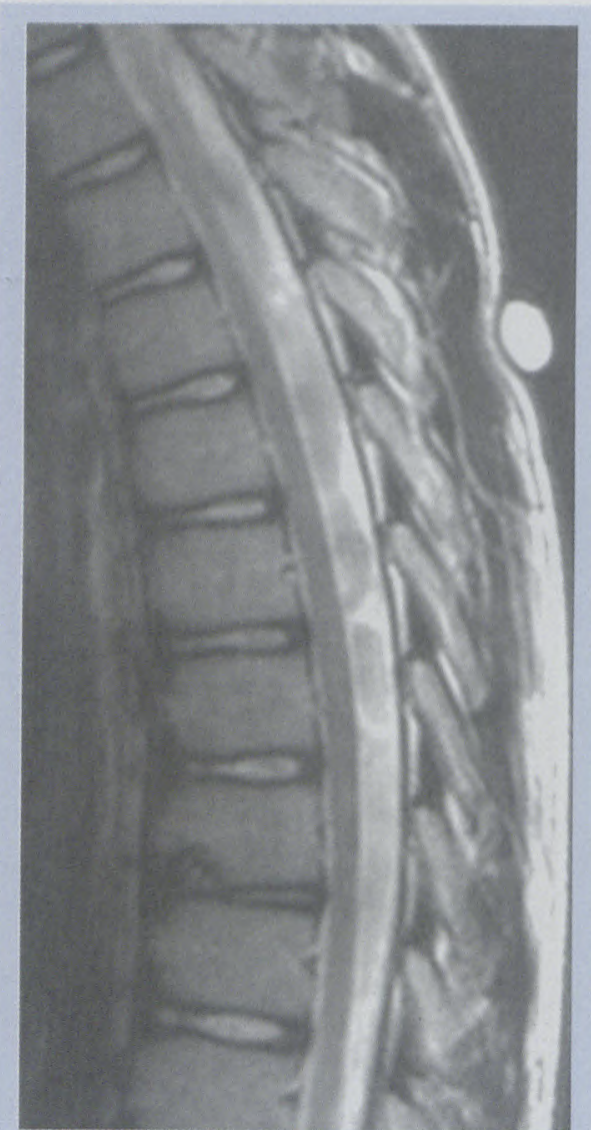

Fig. 4a. Sagittal T2 weighted MR scan of the dorsal spine in a young man with mid-dorsal backache. Plain film studies showed features of Scheuermann's disease. An MR scan was nevertheless performed and multiple 'flow-voids' were reported in the CSF suggesting a possible vascular malformation.

dark peripheral zone or ring due to haemosidern and ferritin deposition in the adjacent normal cord parenchyma (Figs $5 \mathrm{a}, \mathrm{b}$ ). The appearance of a cavernoma can mimic the nidus of a medullary-type arteriovenous malformation (Figs $6 \mathrm{a}-\mathrm{c}$ ). The key differentiating feature is the lack of any associated adjacent flow voids due to dilated feeding arteries and draining veins, which is in keeping with its low-flow status. These lesions are thus also angiographically occult for the same reason.



Fig. 4b. These 'flow-voids' were also seen on the T1 weighted images.



Fig. 4c. Axial T2 images again showing the 'flowvoids'.

\section{References}

1. Lasjaunias P, Berenstein A. Spinal and spinal cord arteries and veins. In: Lasjaunias $\mathrm{P}$, Berenstein A, eds. Surgical Neuroangiography 3: Functional Vascular Anatomy of the Brain, Spinal Cord and Spine. Berlin: Springer-Verlag, 1990: 15-87.



Fig. 4d. The same appearance at another level.

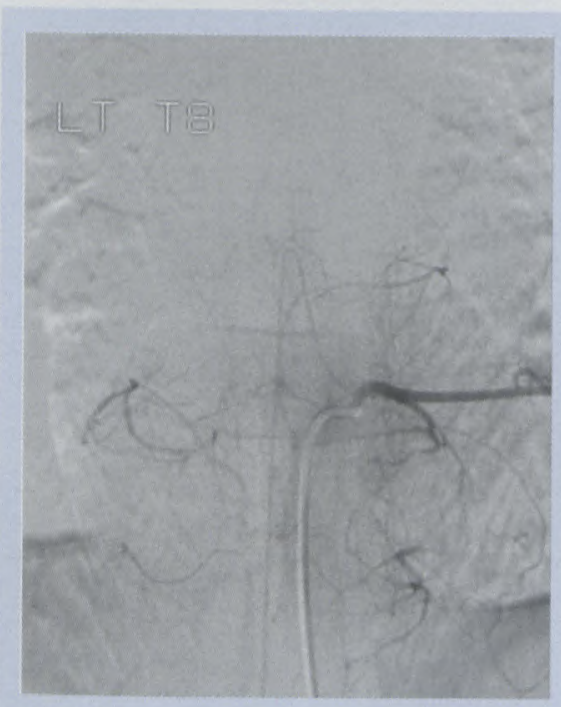

Fig. 4e. An angiogram is performed (under great duress) which is, quite predictably, within normal limits.

2. Ooi Y, Mita F, Satoh Y. Myeloscopic study on lumbar spinal canal stenosis with special reference to intermittent claudication. Spine 1990; 15: 544-549.

3. Cressman MR, Pawl RP. Serpentine myelographic defect caused by a redundant nerve root: Case report. J Neurosurg 1968; 28: 391393.

4. Takahashi M, Yamashita Y, Sakamoto Y, Kojima R. Chronic cervical cord compression: Clinical significance of increased signal intensity on MR images. Radiology 1989; 173: 219-224.

5. Mehalic TF, Pezzuti RT, Applebaum BI. Magnetic resonance imaging and cervical spondylitic myelopathy. Neurosurgery 1990; 26: 217-227.

6. Ogilvy CS, Louis DM, Ojemann RG. Intramedullary cavernous angiomas of the spinal cord: Clinical presentation, pathologic features and surgical management. Neurosurgery 1992; 31: $219-230$. 


\section{PICTORIAL ESSAY}

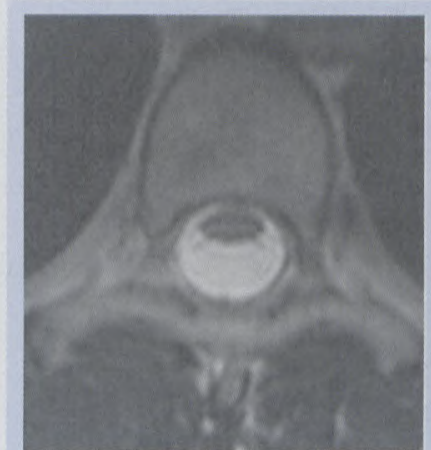

Fig. 4f. To further prove the point the MR scan is repeated on a different machine, this time using a CSF flow suppression sequence (DRIVE or driven equilibrium, Philips), thereby reducing the flowvoid' artefact.

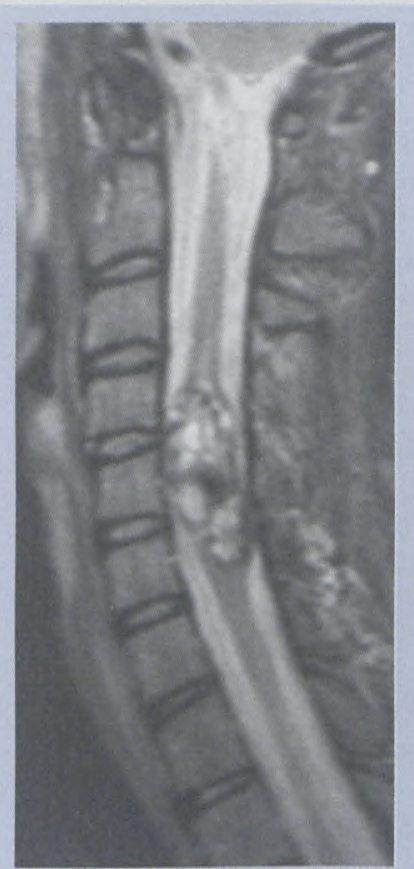

Fig. 5a. Sagittal T2 image showing the typical 'popcorn-like' appearence of an inramedullary cavernoma. Note the surrounding black haemosiderin ring and the lack of any associated flow-voids due to dilated draining veins.



Fig. 5b. Sagittal T1 image showing areas of bright signal in keeping with blood breakdown products at various stages of alteration.



Fig. 6c. Sagittal T2 image, same case, showing the typical appearance of a nidus at the T10 level together with the dilated draining veins.

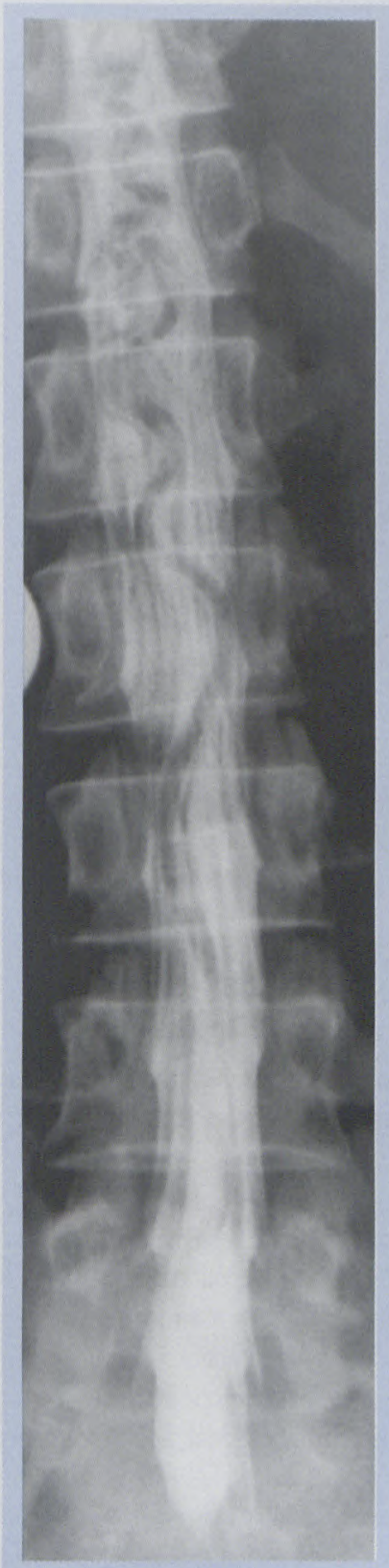

Fig. 6a. A myelograpic study of a patient with a medullary AVM showing multiple serpiginous filling defects due to dilated feeding arteries and draining veins.



Fig. 6b. Coronal T2 image, same case, showing the typical flow-voids seen with a spinal AV shunt. 